Original article

\title{
Transmission dynamics of novel Coronavirus-SARS-CoV-2 in South Sumatera, Indonesia
}

\author{
Rico Januar Sitorus ${ }^{\mathrm{a}, \mathrm{d}, \text { * }}$, Irzanita Wathan ${ }^{\mathrm{d}}$, Hibsah Ridwan ${ }^{\mathrm{b}}$, Hariadi Wibisono ${ }^{\mathrm{b}}$, Lesti Nuraini ${ }^{\mathrm{c}}$, \\ Yusri $^{\mathrm{c}}$, Gandi Kosim ${ }^{\mathrm{b}}$, Nugi Nurdin ${ }^{\mathrm{c}}$, Hatta Mamat ${ }^{\mathrm{c}}$, Iche Andrayani ${ }^{\mathrm{a}}$, Nyoman Yudi Antara ${ }^{\mathrm{d}}$, \\ Merry Natalia ${ }^{\mathrm{e}}$
}

\footnotetext{
a Department of Epidemiology Public Health Faculty Sriwijaya University, Indonesia

${ }^{\mathrm{b}}$ Indonesia Epidemiological Association, Indonesia

${ }^{\mathrm{c}}$ Health Office of Province of South Sumatra, Indonesia

${ }^{\mathrm{d}}$ Faculty of Health University of Kader Bangsa, Palembang, Indonesia

${ }^{\mathrm{e}}$ Port Health Office, Ministry of Health of Indonesia, Indonesia
}

\section{A R T I C L E I N F O}

\section{Keywords:}

Close contact

Travel history

Transmission dynamics

Sars-cov-2

\begin{abstract}
A B S T R A C T
SARS-CoV-2 has shaken the world by extremely raising death tolls, illnesses, and economic losses. The virus is transmitted by humans to other humans, spreading to more than 200 countries. This research aims to analyze the transmission dynamics of novel Coronavirus-SARS-CoV-2 in South Sumatera Indonesia. This is epidemiologic research, and the research population is all SARS-CoV-2 patients and those who have close contact with the patients in all districts/cities in South Sumatera. It has been widely known that those that have made contact with patients confirmed positive for SARS-CoV-2 has a risk of getting infected by SARS-CoV-2 by 3.591 higher than those who never have (OR $=3.591,95 \% \mathrm{CI}$ : 2.933-4.396). Also, according to the findings, those who have a contact history to patients confirmed positive for SARS-CoV-2 have a risk of getting infected by SARS-CoV-2 by 2.387 higher than those who never have (OR $=2.387,95 \% \mathrm{CI}: 1.362-4.184)$. Meanwhile, those who have no idea for having made contact with patients confirmed positive for SARS-CoV-2 has a risk of getting infected by SARS-CoV-2 by 1.082 higher than those who have never a contact history to the SARS-CoV- 2 patients (OR = 1.082, 95\% CI: 0.622-1.882). To prevent broader transmission, those who have made contact with the SARSCoV-2 patients need to be quarantined. The findings help us give community health interventions to globally fight this transmittable disease.
\end{abstract}

\section{Introduction}

Systemic respiratory disease in humans is the Severe Acute Respiratory Syndrome Coronavirus 2 (SARS-CoV-2). ${ }^{1,2}$ SARS-CoV-2 is a communicable disease transmitted by a novel Coronavirus and belongs to a virus family identifiable in animals. Patients infected by SARS-CoV-2 will experience mild to moderate respiratory issues and may recover without any exclusive treatment. However, older people with comorbidities e.g. cardiovascular diseases and cancers may suffer from the severity and even death. ${ }^{3}$

The first COVID-19 case in Indonesia reportedly occurred on March 2nd, 2020, and consistently spread to and increased in other areas. SARS-CoV-2 infects people rapidly and has an incubation period of 5-12 days. ${ }^{4}$ SARS-CoV-2 may contract those with mild symptoms and even those without any indication of symptoms. ${ }^{5,6}$ You may contract SARS-CoV-2 from those who have been infected through their coughs or sneezes or saliva. ${ }^{7}$ The rate of infection spread indicates strong evidence of secondary transmission from humans to humans. This transmission is allegedly triggered by a travel history. For example, 14 cases detected in the US involved a trip to China or close contact with travellers. 3 of the 14 cases were detected in the US citizens transferred from China. Also, 42 cases were identified in passengers transferred from a cruiser which sailed to the centre of the epidemic. ${ }^{8}$ To prevent a broader transmission, quarantines should be enacted and cross-country transmission should be prevented. ${ }^{9}$ Nevertheless, an inaccurate risk assessment and reporting can increase the potency of SARS-CoV-2 to spread globally. ${ }^{10}$ Contact tracing and testing are thus required to lessen the rate of SARS-CoV-2 infection spread. ${ }^{11}$

\footnotetext{
* Corresponding author. Department of Epidemiology Public Health Faculty Sriwijaya University.

E-mail address: rico_januar@fkm.unsri.ac.id (R.J. Sitorus).
} 
As it is pivotal to mitigate the spread of SARS-CoV-2, patients with mild symptoms should self-quarantine and must not make a long trip. Human-to-human transmission can incur due to close contact which must be prevented. Therefore, the government should enact a selfquarantine program and travel restriction. Each outbreak provides an opportunity to acquire important information regarding the outbreak so the identification of potential types of exposure has important implications for containment and mitigation strategies. As such, this research aims to investigate the transmission dynamics of SARS-CoV-2 in a population.

\section{Methods}

The research design used is cross-sectional. The research population is all SARS-CoV-2 patients and those who have made contact with the patients. This research is conducted in all districts/cities in South Sumatera. Data collection was performed in June-September 2020. The data collection instrument used is the instrument for an epidemiological investigation developed by the Indonesia Epidemiological Association in cooperation with the CDD Foundation and inputted to Kobo.humanitarianresponse. Research respondents are all SARS-CoV-2 patients and those who have made close contact and are selected using a total sampling technique.

\subsection{Data collection}

Sex, occupation, and the history of close contact with SARS-CoV-2 patients are three independent variable variables with two categories, while the history of traveling abroad, visiting local transmission region, visiting health facilities, contact with suspects, contact with patients confirmed positive are divided into three categories. The independent variables comprise three categories which are confirmed cases, probable cases, and suspect cases. The bias which may incur during research is non-response bias from patients. To mitigate the bias impacts, we explain the research objectives and approaches by a means of public figures. Crosschecking the close contacts identified is conducted using the information we acquire from many sources. Besides, households and places which have been visited by patients within the last two weeks before the symptoms appear are also investigated to measure environmental exposure. 2203 samples are inputted in Kobo.humanitarianresponse. The data inputted were cleaned and thereby remaining 2137 respondents proceed to the analysis. Meanwhile, the data which cannot be analyzed are incomplete answers.

\subsection{Data analysis}

Furthermore, in terms of statistical analysis using a Chi-square test, Simple logistic regression, and double logistic regression, the dependent variables are divided into two categories based on the result of the investigations of confirmed cases and non-confirmed cases. Confirmedpositive cases are cases which have been identified using a Swab test, whereas non-confirmed cases are cases which have not been identified and come with two categories: probable and suspect cases. A Chi-square test is used to compare the dissimilarities between patients confirmed positive for COVID-19 and those not confirmed positive at a significance level of $\mathrm{p}<0.05$. The continue valuable and category are presented as a mean and an absolute number (percentage). Moreover, the double logistic regression analysis is made to examine factors predicting the prevalence of COVID-19 cases. The covariate selection of the final multivariable model is built upon whether the variable has fulfilled the criteria of $\mathrm{p}<0.25$ in the simple logistic regression and whether it constitutes the theoretical/clinical research interests. The variables assessed are sex, occupation, history of traveling abroad, history of visiting health facilities, history of contact with suspects, history of contact with patients confirmed positive for COVID-19, and close contacts.

\section{Results}

\subsection{Patient characteristic}

There are 2137 respondents, the majority of whom, $52 \%$, are male. Most respondents are 38.19 years old and work as entrepreneurs (12.7\%). (Table 1).

\subsection{Predictors of intention to Covid-19}

The findings indicate that sex and occupation do not pertain to SARSCoV-2. Meanwhile, the history of traveling abroad, visiting local transmission areas, visiting health facilities, contact with suspects, contact with patients confirmed positive for COVID-19, and close contacts are deemed as the significant predictors of the SARS-CoV-2 transmission and proceed to the multivariate analysis. Table 2 .

In Table 3, the predominant variable predicting the prevalence of SARS-CoV-2 is close contact with patients confirmed positive. Those who have made close contacts with SARS-CoV-2 patients have a risk to get infected by SARS-CoV-2 3591 higher 3.591 than those who have never (OR $=3.591,95 \%$ CI: 2.933-4.396). Besides, those who have made a history of contacts with SARS-CoV-2 patients have a risk to get infected by SARS-CoV-2 2.387 higher than those who have never (OR = 2.387, 95\% CI: $1.362-4.184$ ). Meanwhile, those who are unaware of having contacts with SARS-CoV-2 patients have a risk to get infected by SARS-CoV-2 1.082 higher than those who have never made contact with them $(\mathrm{OR}=1.082,95 \%$ CI: $0.622-1.882)$. Model $x^{2}$ is 59.7 (degrees of free-dom $=10, p$ 0.0001) and the Hosmer-Lemeshow test is not significant $(\mathrm{p}=0.048)$, indicating a good model fit. Nagelkerke $\mathrm{R}^{2}$ is 0.208 , which means that $20.8 . \%$ variability in the prevalence of COVID-19 by the variables included in the model.

\section{Discussion}

This research aims to assess the prevalence of SARS-CoV-2 and determine what factors predicting the prevalence of SARS-CoV-2 cases. Respondents infected by SARS-CoV-2 who have made close contact with those infected are the predominant predictors. $45.6 \%$ of respondents

Table 1

Characteristic sociodemographic respondence

\begin{tabular}{ll}
\hline Sociodemographic characteristics & Finding \\
\hline Age (years) & \\
(Mean + Standard deviation) & $38.19+17.32$ \\
Sex & \\
Male & $1111(52 \%)$ \\
Female & $1026(48 \%)$ \\
Job & \\
Day laborer & $89(4.2 \%)$ \\
Pharmacist & $8(0.4 \%)$ \\
Accounting & $36(1.7 \%)$ \\
Medical worker & $182(8.5 \%)$ \\
Artist & $1(0.01 \%)$ \\
Factory worker & $42(2 \%)$ \\
Traders & $72(3.4 \%)$ \\
Public service & $111(5.2 \%)$ \\
Institution & $90(4.2 \%)$ \\
Businessman & $19(0.9 \%)$ \\
Fishery & $4(0.2 \%)$ \\
Forestry & $3(0.1 \%)$ \\
Mining & $24(1.1 \%)$ \\
Farmer & $79(3.7 \%)$ \\
Government employees & $199(9.3 \%)$ \\
Information technology & $3(0.1 \%)$ \\
Merchants & $1(0.01)$ \\
Army & $58(2.7 \%)$ \\
Transportation & $28(1.3 \%)$ \\
Entrepreneur & $271(12.7 \%)$ \\
Unemployed & $817(38.2 \%)$ \\
\hline
\end{tabular}


Table 2

Predictors of the incidence of SARS-CoV-2.

\begin{tabular}{|c|c|c|c|c|c|c|}
\hline \multirow[t]{3}{*}{ Variable } & \multirow[t]{3}{*}{ Category } & \multicolumn{4}{|c|}{ Covid-19 cases } & \multirow{3}{*}{$\begin{array}{l}\mathrm{p}- \\
\text { value }\end{array}$} \\
\hline & & \multicolumn{2}{|c|}{ Confirmed } & \multicolumn{2}{|c|}{$\begin{array}{l}\text { Unconfirmed } \\
\text { (probable }+ \\
\text { suspect) }\end{array}$} & \\
\hline & & $\mathrm{n}$ & $\%$ & $\mathrm{n}$ & $\%$ & \\
\hline \multirow[t]{2}{*}{ Sex } & Male & 681 & 61.3 & 430 & 38.7 & 0.921 \\
\hline & Female & 632 & 61.6 & 394 & 38.4 & \\
\hline \multirow[t]{2}{*}{ Job } & Employee & 815 & 61.7 & 505 & 38.3 & 0.751 \\
\hline & unemployed & 498 & 61 & 319 & 39 & \\
\hline \multirow[t]{3}{*}{ Abroad travel history } & Yes & 7 & 58.3 & 5 & 41.7 & 0.015 \\
\hline & Unknown & 17 & 94.4 & 1 & 5.6 & \\
\hline & No & 1289 & 61.2 & 818 & 38.8 & \\
\hline \multirow{3}{*}{$\begin{array}{l}\text { Local transmission } \\
\text { history }\end{array}$} & Yes & 96 & 50.8 & 93 & 49.2 & 0.0000 \\
\hline & Unknown & 60 & 92.3 & 5 & 7.7 & \\
\hline & No & 1157 & 61.4 & 726 & 38.6 & \\
\hline \multirow{3}{*}{$\begin{array}{l}\text { Medical facility } \\
\text { visitation history }\end{array}$} & Yes & 195 & 77.4 & 57 & 22.6 & 0.0000 \\
\hline & Unknown & 73 & 92.4 & 6 & 7.6 & \\
\hline & No & 1045 & 57.9 & 761 & 42.1 & \\
\hline \multirow{3}{*}{$\begin{array}{l}\text { Contact history with } \\
\text { suspect }\end{array}$} & Yes & 138 & 63.3 & 80 & 36.7 & 0.0000 \\
\hline & Unknown & 235 & 81.6 & 53 & 18.4 & \\
\hline & No & 940 & 57.6 & 691 & 42.4 & \\
\hline \multirow{2}{*}{$\begin{array}{l}\text { Contact history with } \\
\text { confirmed case }\end{array}$} & Yes & 456 & 72.8 & 170 & 27.2 & 0.0000 \\
\hline & $\begin{array}{l}\text { Unknown } \\
\text { No }\end{array}$ & 189 & 76.2 & 59 & 23.8 & \\
\hline \multirow[t]{2}{*}{ Close contact } & Yes & 742 & 76.2 & 232 & 23.8 & 0.0000 \\
\hline & No & 571 & 49.1 & 592 & 50.9 & \\
\hline
\end{tabular}

Table 3

Multivariate analysis of the incidence of SARS-CoV-2.

\begin{tabular}{|c|c|c|c|c|}
\hline Risk Factors & Category & $\beta$ & $\begin{array}{l}\mathrm{p}- \\
\text { value }\end{array}$ & OR $(95 \% \mathrm{CI})$ \\
\hline \multirow{3}{*}{$\begin{array}{l}\text { History of local } \\
\text { transmission area }\end{array}$} & No & & & Reff \\
\hline & Unknown & $\begin{array}{l}- \\
1.949\end{array}$ & 0.000 & $\begin{array}{l}0.142 \\
(0.049-0.412)\end{array}$ \\
\hline & Yes & $\begin{array}{l}- \\
0.812\end{array}$ & 0.121 & $\begin{array}{l}0.444 \\
(0.159-1.241)\end{array}$ \\
\hline \multirow{3}{*}{$\begin{array}{l}\text { Medical facility visitation } \\
\text { history }\end{array}$} & No & & & Reff \\
\hline & Unknown & $\begin{array}{l}- \\
0.759\end{array}$ & 0.122 & $\begin{array}{l}0.468 \\
(0.179-1.224)\end{array}$ \\
\hline & Yes & $\begin{array}{l}- \\
1.470\end{array}$ & 0.002 & $\begin{array}{l}0.230 \\
(0.091-0.579)\end{array}$ \\
\hline \multirow{3}{*}{$\begin{array}{l}\text { Contact history with } \\
\text { suspect }\end{array}$} & No & & & Reff \\
\hline & Unknown & - & 0.007 & $\begin{array}{l}0.435 \\
(0.238-0.794)\end{array}$ \\
\hline & Yes & $\begin{array}{l}- \\
1.020\end{array}$ & 0.000 & $\begin{array}{l}0.361 \\
(0.206-0.632)\end{array}$ \\
\hline \multirow{3}{*}{$\begin{array}{l}\text { Contact history with } \\
\text { confirmed case }\end{array}$} & No & & & Reff \\
\hline & Unknown & 0.078 & 0.781 & $\begin{array}{l}1.082 \\
(0.622-1.882)\end{array}$ \\
\hline & Yes & 0.870 & 0.002 & $\begin{array}{l}2.387 \\
(1.362-4.184)\end{array}$ \\
\hline \multirow[t]{2}{*}{ Close contact } & No & & & Reff \\
\hline & Yes & 1.278 & 0.000 & $\begin{array}{l}3.591 \\
(2.933-4.396)\end{array}$ \\
\hline
\end{tabular}

Notes: OR: Odd Ratio, CI: Confidence Interval.

infected by SARS-CoV-2 admit to having made close contact with SARS$\mathrm{CoV}-2$ patients. A contact is considered close when those experiencing it is having a contact within $1 \mathrm{~m}$ in distance to patients confirmed and suspected positive two days before the appearance of symptoms in the patients confirmed and suspected or two days before the asymptomatic infection sample is collected. ${ }^{12}$
As a preventive effort regarding a broader transmission, quarantine is an obligation for those who have made close contact with SARS-CoV-2 patients. According to clinical tests, the virus needs 1-14-day incubation, but the majority of which takes 3-7 days. Quarantine is supposed to last for 14 days, or within the incubation period of SARS-CoV-2. However, evidence suggests that quarantine may be extended to 21 days. ${ }^{13}$ Chen et al. (2020) argue that the dissimilarities in transmission through close contact between the two groups are statistically insignificant. ${ }^{14}$ Close contact with SARS-CoV-2 patients may happen in a family and a group of friends, either close friends or working partners. Transmission through close contact within a family is high in prevalence. It may occur between a husband and wife and in a group of people who share a house or plate when eating. ${ }^{15-18}$ SARS-CoV-2 has pathogenicity and transmission stronger than SARS-CoV and MERS-CoV. ${ }^{10}$ Contacting a patient confirmed positive, being close for 15 of $50 \mathrm{~s}$, and leaving the mask are the factors of infection. ${ }^{9,19}$

SARS-CoV-2 brings about a cluster transmission, especially in a family. The prevalence of MERS transmission between family members is $13-21 \%$, while that of SARS transmission is $22-39 \% .{ }^{20}$ Although the family member infected has been hospitalized, they might have transmitted the virus to another family member. SARS-CoV-2 can also be transmitted through fesses and the virus can survive within 1-2 days in fesses. ${ }^{21,22}$ Our findings also prove that the history of traveling abroad/to other regions (local transmission) may increase the transmission risks. Early detection of imported cases should be activated in the countries which have such potentials. An imported case reportedly incurs in Brazil as one of its citizens travelled to Italy, one of the countries with high cases of SARS-CoV-2. ${ }^{23}$ Furthermore, travel restrictions can mitigate the broadened transmission across countries besides the public health interventions and behavioural changes that can facilitate the mitigation. ${ }^{24,25}$ This research gives valid evidence which supports the argument that asymptomatic human-to-human SARS-CoV-2 transmission can be through close contact, contact with SARS-CoV-2 patients, trips to other countries, or local transmission. This research allows us to make public health interventions to fight this communicable disease globally.

\section{Ethical statement}

All study materials, including research protocols, were approved by health research ethics committee, faculty of public health Sriwijaya University description of ethical approval "Ethical Approval"No: 127/ un9.1.10/kke/2020. All participants gave their informed consent before their data were collected.

\section{Declaration of competing interest}

The authors declare that there is no conflict of interests regarding the publication of this paper.

\section{Acknowledgment}

All authors are supported by the Indonesia Epidemiological Association, CDC Foundation, Health Office of South Sumatra, all District and City Health Offices in South Sumatra.

\section{References}

1 Al-Rousan N, Al-Najjar H. The Correlation between the Spread of COVID-19 Infections and Weather Variables in 30 Chinese Provinces and the Impact of Chinese Government Mitigation Plans. 2020.

2 Adhikari SP, Meng S, Wu Y-J, et al. Epidemiology, causes, clinical manifestation and diagnosis, prevention and control of coronavirus disease (COVID-19) during the early outbreak period: a scoping review. Infect Dis poverty. 2020;9(1):1-12.

3 Huang C, Wang Y, Li X, et al. Clinical features of patients infected with 2019 novel coronavirus in Wuhan, China. Lancet. 2020;395(10223):497-506.

4 Lauer SA, Grantz KH, Bi Q, et al. The incubation period of coronavirus disease 2019 (COVID-19) from publicly reported confirmed cases: Estimation and application. Ann 
Intern Med [Internet]. 2020 Mar 10;172(9):577-582. https://doi.org/10.7326/M200504. Available from:.

5 Ramanathan K, Antognini D, Combes A, et al. A Familial Cluster of Pneumonia Associated with the 2019 Novel Coronavirus Indicating Person-To-Person Transmission: A Study of a Family Cluster. 2020:19-21 (January).

6 Rothe C, Schunk M, Sothmann P, et al. Transmission of 2019-NCOV infection from an asymptomatic contact in Germany. N Engl J Med. 2020;382(10):970-971.

7 Peeri NC, Shrestha N, Rahman MS, et al. The SARS, MERS and novel coronavirus (COVID-19) epidemics, the newest and biggest global health threats: what lessons have we learned? Int J Epidemiol. 2020;0:1-10. https://doi.org/10.1093/ije/ dyaa033, 0 .

8 Covid CDC COVID CDC, Chow N, Fleming-Dutra K, Gierke R, et al. Preliminary estimates of the prevalence of selected underlying health conditions among patients with coronavirus disease 2019-United States, February 12-March 28, 2020. Morb Mortal Wkly Rep. 2020;69(13):382. COVID CDC.

$9 \mathrm{Li}$ Q, Guan X, Wu P, et al. Early transmission dynamics in Wuhan, China, of novel coronavirus-infected pneumonia. N Engl J Med. 2020;382:1199-1207. https://doi. org/10.1056/NEJMoa2001316, 13.

10 Novel CPERE. The epidemiological characteristics of an outbreak of 2019 novel coronavirus diseases (COVID-19) in China. Zhonghua liu xing bing xue za zhi= Zhonghua liuxingbingxue zazhi. 2020;41(2):145.

11 Kretzschmar ME, Rozhnova G, Bootsma MCJ, van Boven M, van de Wijgert JHHM, Bonten MJM. Impact of delays on effectiveness of contact tracing strategies for COVID-19: a modelling study. Lancet Public Heal [Internet]. 2020;5(8):e452-e459. https://doi.org/10.1016/S2468-2667(20)30157-2. Available from:.

12 Miao Yang L, Chu H, Fan MengRong X. Effect of delay in diagnosis on transmission of COVID-19. Math Biosci Eng. 2020;17(3):2725-2740.

13 Wang S-X, Wang Y, Lu Y-B, et al. Diagnosis and treatment of novel coronavirus pneumonia based on the theory of traditional Chinese medicine. J Integr Med. 2020/ 04/15;18(4):275-283, 2020 Jul.
14 Chen Y, Wang A, Yi B, et al. The epidemiological characteristics of infection in close contacts of COVID-19 in Ningbo city. Chin J Epidemiol. 2020;41(5):668-672.

15 Jing Q-L, Liu M-J, Zhang Z-B, et al. Household secondary attack rate of COVID-19 and associated determinants in Guangzhou, China: a retrospective cohort study. Lancet Infect Dis. 2020;20(10):1141-1150.

$16 \mathrm{Li} \mathrm{W}$, Zhang B, Lu J, et al. The characteristics of household transmission of COVID19. Clin Infect Dis. 2020;71(8):1943-1946, 8 https://doi.org/10.1093/cid/ciaa450.

17 Chen N, Zhou M, Dong X, et al. Epidemiological and clinical characteristics of 99 cases of 2019 novel coronavirus pneumonia in Wuhan, China: a descriptive study. Lancet. 2020;395(10223):507-513.

18 Hui DS, Azhar EI, Kim Y-J, Memish ZA, Oh M, Zumla A. Middle East respiratory syndrome coronavirus: risk factors and determinants of primary, household, and nosocomial transmission. Lancet Infect Dis. 2018;18(8):e217-e227.

19 Deng T, Huang Y, Yu S, et al. Spatial-temporal clusters and risk factors of hand, foot, and mouth disease at the district level in Guangdong Province, China. PloS One. 2013 Feb;8(2), e56943. e56943.

20 Yin Y, Wunderink RG. MERS, SARS and other coronaviruses as causes of pneumonia. Respirology. 2018;23(2):130-137.

21 Chan K-H, Sridhar S, Zhang RR, et al. Factors affecting stability and infectivity of SARS-CoV-2. J Hosp Infect. 2020;106(2):226-231.

22 Chen Y, Guo Y, Pan Y, Zhao ZJ. Structure analysis of the receptor binding of 2019nCoV. Biochem Biophys Res Commun. 2020;525:135-140. https://doi.org/10.1016/j. bbrc. 2020.02.071.

23 Candido DDS, Watts A, Abade L, et al. Routes for COVID-19 importation in Brazil. J Trav Med. 2020 May;27(3).

24 Chinazzi M, Davis JT, Ajelli M, et al. The effect of travel restrictions on the spread of the 2019 novel coronavirus (COVID-19) outbreak. Science. 2020;368(6489):395-400 (80-).

25 Drake JM, Chew SK, Ma S. Societal learning in epidemics: intervention effectiveness during the 2003 SARS outbreak in Singapore. PloS One. 2006;1(1), e20. 